\begin{tabular}{ccc}
\hline Strain or Plasmid & Description & Reference $^{*}$ \\
Klebsiella pneumoniae & $\Delta($ bla $)-2 \mathrm{KC} 2668$ & \\
EG13127 & $\Delta($ bla $)-2 \Delta p m r D:: \mathrm{Kn}^{\mathrm{R}}$ & Ref. ([1]) \\
EG14740 & $\Delta($ bla $)-2 \Delta p m r A:: \mathrm{Kn}^{\mathrm{R}}$ & Ref. ([25]) \\
EG13129 & $\Delta(b l a)-2 \Delta p h o P:: \mathrm{Kn}^{\mathrm{R}}$ & This work \\
EG15289 & $\Delta(b l a)-2 \Delta p b g P:: \mathrm{Kn}^{\mathrm{R}}$ & This work \\
EG14735 & $\Delta(b l a)-2 \quad \mathrm{Kn}^{\mathrm{R}}-p b g P^{+}$ & This work \\
EG16126 &
\end{tabular}

\title{
Salmonella enterica
} serovar Typhimurium

\begin{tabular}{|c|c|c|}
\hline $14028 s$ & Wild-type & Ref. ([26]) \\
\hline EG17353 & p pbgP Yersinia & This work \\
\hline EG17354 & $\mathrm{p}_{p b g}$ Y Yersinia $p m r D 1:: \mathrm{Cm}$ & This work \\
\hline EG17235 & $p_{p b g} p:: t e t R A$ & Ref. ([5]) \\
\hline EG17343 & $\mathrm{p}_{p b g} P:: t e t R A$ pmrD1::Cm & This work \\
\hline EG11491 & $p m r D 1::$ Cat & Ref. ([6]) \\
\hline
\end{tabular}

\section{Plasmids}

\begin{tabular}{ccc} 
pAG & $\operatorname{rep}_{\mathrm{p} 15 \mathrm{~A}} \operatorname{Tet}^{\mathrm{R}} g f p$ mut3a & Ref. ([7]) \\
pAG-pmrDKlebsiella & rep $15 \mathrm{~A}^{\text {Tet }^{\mathrm{R}}} g f p$ mut3a PpmrD & \\
& & \\
\hline
\end{tabular}




\begin{tabular}{|c|c|c|}
\hline pAG-rpsM & repp15A $_{\text {Tet }}^{\mathrm{R}} g f p$ mut3a PrpsM & Ref. ([7]) \\
\hline pKD3 & repR6к ${ }_{\gamma} \mathrm{Ap}^{\mathrm{R}} \mathrm{FRT} \mathrm{Cm}^{\mathrm{R}} \mathrm{FRT}$ & Ref. ([3]) \\
\hline pKD4 & repR6K $_{\gamma} \mathrm{Ap}^{\mathrm{R}} \mathrm{FRT} \mathrm{Kn}^{\mathrm{R}} \mathrm{FRT}$ & Ref. ([3]) \\
\hline pKD46 & $\operatorname{rep}(\text { ts })_{p s c 101} A_{p}^{R} p_{\text {araBAD }} \gamma \beta$ exo $^{+}$ & Ref. ([3]) \\
\hline
\end{tabular}

*The references are provided in Text S1 